\title{
Psychological and pedagogical aspects of international students' adjustment to the cultural and educational university environment
}

\author{
Fatimet Khakunova ${ }^{1,{ }^{*}}$, Asya Bersirova ${ }^{1}$, Nurbyi Khakunov $^{1}$ and Safiat Bersirova ${ }^{1}$ \\ ${ }^{1}$ Adyghe State University, Maykop, Russia
}

\begin{abstract}
International students represent different cultures and differ psychologically, ethnically and culturally from citizens of their host country [1]. This causes adjustment problems in their new socio-cultural environment. The educational establishment should modernize and improve learning conditions which enables international students to adapt faster, develop their abilities and skills, improve their educational prospects. Purpose of the study was to draw out and experimentally substantiate psycho-pedagogical conditions and factors of successful adjustment to the educational environment for the international university students. Highly adaptive international students belong to the interactive type. They exhibit immersion readiness in unfamiliar intercultural conditions, striving to broaden their social circle with representatives of other cultures, aim at joint problem-solving, while exhibiting fewer signs of loneliness. By reference to students with lower adjustment levels, they exhibit medium manifestation of psycho-emotional symptomatology signs together with affective and cognitive components of ethnic identity [2]. They exhibit medium levels of cultural shock, tolerance, social distancing and average subjective wellbeing. These features are common for the unfinished adjustment process among international students. Thusly, we distinguish external and intrinsic factors which influence smooth adjustment process. The results of the study demonstrate that intercultural adjustment of international students is more successful in compliance with the support program implemented according to socio-psychological traits of international students and newly existing conditions of socio-cultural environment. The support program encompasses main areas of student life, which is a distinct advantage [3]. Its adaptable structure adjusts to all possible alterations to be implemented in various groups and different conditions.
\end{abstract}

\section{Introduction}

According to the Ministry for Education and Science statistics, Russia ranks as number eight in the world for total number of international students. Recent studies show that educating international students became a priority for international cooperation of the higher professional education system.

\footnotetext{
* Corresponding author: pedagog-psycholog84@mail.ru
} 
When choosing a higher educational establishment international students employ a number of principles. A most important one is the overall quality of educational services which directly correlates with the adjustment process to the unfamiliar learning environment. International students represent different cultures and differ psychologically, ethnically and culturally from the citizens of their host country. This causes adjustment problems to their new social and cultural environment. The educational establishment in question aims at modernizing and improving learning conditions which makes it possible for international students to adapt faster, develop their abilities and skills and improve their educational prospects. Increasing numbers of international students within Russian system of higher education and positive learning environment result in additional interest, particularly when studying adjustment peculiarities in wholly unfamiliar educational and living conditions. Thus, the following works became objects of study: Merenkov and Antonova (2013), Drozhzhina (2013), Stepanova (2014), Vaulina and Konoshenko (2014), Kozulina (2015), Pogukaeva and Kobernik (2016), Chechkaryova (2016) [4].

Problems of educating international students are object of scientific research in the works of Belous, Adamenko, Palka, Grutsyak, Khristinko, Pazorenov, Bulkakova, Varavva, Dementyeva and others. Shtak distinguished biological, social and psychological forms of individual adjustment to changing environmental conditions [5]. Miloslavova brought out the issue of methodogically researching the adjustment process, considering socio-psychological adjustment from a professional standpoint [6]. While studying socio-psychological adjustment Rean views it as adaptable by the subject according to the situation, thus distinguishing three fields of research:

1) co-relation of psycho-analytic guidelines, interrelations between personalities and social environment;

2) analysis of humanistic psychology;

3) cognitive social psychology trend. [7].

Emphasizing that the subject is not only a living organism but a complex bio-social system, Morozov insists on compulsory research of human adjustment issues. He distinguishes three functional levels: physiological, psychological and social [8]. Furthermore, he speaks of distinct adaptation venues: mental and psychosomatic. According to Tairova, the necessity for adjustment of international students to the unfamiliar social and cultural surroundings encompasses two standpoints: the subject as a representative of his country and culture and his her personal traits, features and views as a student [9]. Maklakov views complex mechanisms of physiological, mental and social adjustment as a unit and as independent components. Concurrently he stresses out that there are specific physiological and mental mechanisms ensuring a three-level adjustment process [10]. These three interrelated levels directly define a unified course of action of human organism as a system. Integral characteristic is a functional state of a body which in itself is a rather dynamic entity.

Shaglina, Trusov, Ivanova and Titkova researched the possibilities of consciously controlling adjustment processes among international students by implementing a system of study motivation, complex pedagogical impact within a positive learning environment and increasing the effectiveness of the study process on the basis of social and psychological adaptiveness [11].

The study shows that the researches take more interest in the psyche of their international subjects than their socialization and adjustment processes. We believe that their ambient environment, language difficulties, foreign culture, university environment largely factor in the internal changes in the subjects' personality structure, which demands a distinct attention shift from researches involved. Organizational issues of educational process and conditions for successful intercultural adjustment of international students in Russia remain largely understudied. 
According to the statistical data for 2019, in the Republic of Adygea, in Maykop, and, particularly at ASU, there are over two thousand international students. Under the circumstances, the adjustment process to the unfamiliar multicultural and socio-cultural conditions of university life is considered a crucial factor in defining the effectiveness of the educational process for the international students. Thusly, all measures taken by the university authorities to ensure adjustment of international students are of intrinsic importance at this stage of social development, which contributes to the relevance of this study.

Purpose of the study was to draw out and experimentally substantiate psychological and pedagogical conditions and factors of successful adjustment to the educational environment for the international university students. Subject of research included psychological and pedagogical adjustment conditions of international students to the cultural and educational university environment.

Research hypothesis: international students' adjustment process to the cultural and educational environment may be considered successful if:

- international students achieve a high level of ethnical tolerance;

- levels of marked cultural shock, detachment and social distancing with the host culture representatives decrease;

- interactive adjustment will be used when working with international students;

- international students develop intrinsic motivation aimed at receiving formidable education and socio-cultural adjustment.

\section{Methodological basis}

The three-phase experimental study was conducted at Adyghe State University (ASU) in 2018-2019. Empiric study included international students of every study year, from first to fourth (18-30 y.o.). Particularly noteworthy, that the majority of international students (about $90 \%$ ) reside in student hostels provided by their host educational establishments. The study had 53 subjects in total ( 28 female and 25 male students). The majority of subjects are ethnic Turkmen (35 students), 9 students are from Syria, 2 from Turkey and 1 from Mongolia. Average age was 22 years old.

We chose the means of psychodiagnostics by using contemporary methods for psychological assessment for the main empirical research. Phinney technique enabled us to calculate the level of ethnic unity and to study its cognitive and emotional component [12]. A quick questionnaire "Tolerance index" (by Soldatova, Kravtsova, Khukhlaeva, Shaigerova) exposed a number of tolerance measurements (ethnic, social and personal) and prompted their analysis [13]. The guidance manual of cultural shock manifestation levels (by Mnatsakanyan) defined cultural shock levels and enabled to analyze emotional manifestations, such as anxiety level; feeling of detachment and isolation; identity issues; feeling of incompetence; communicative angst; misgivings over quality of food and service; home sickness [14]. The Bogardus scale of social distancing revealed social distancing range with representatives of a different culture [15]. Sholokhov's intercultural adjustment questionnaire defined social adjustment levels among international students to new learning and living conditions, unearthing existing problems [16]. Several aspects of student adjustment were studied, namely: adjustment to new conditions; tolerance towards a foreign society and objective assessment of your part in it; language difficulties; educational motivation. Personal adaptiveness to new socio-cultural environment test (or Yankovsky test) showed adjustment levels and the subjects' individual measurements, such as: depression, adaptiveness, comfort, interactivity, detachment, homesickness [17].

Our university student questionnaire (copyright), enabled us to gauge both the attitude of international students towards educational and tenancy factors as well as problems they 
encounter. The questionnaire included an improvement: variable answer characteristic, which, by employing the quantitative approach allowed us to study interrelations between phenomena and form influences on the learning process, inconsistencies in between groups and much more. The questionnaire comes in three languages (Turkmenian, English and Russian). This simplified the research process. Our coded work sheet speeded primary processing of the questionnaire results.

\section{Results}

The majority of research subjects have been living on the territory of Russia for the last 1-3 years. Most state their reasons for studying in Russia as easier terms of enrollment $(31,6 \%)$ and better job prospects $(22,8 \%)$. More than $27 \%$ of the surveyed replied to the question «how did you prepare for the trip»: they studied Russian at school; 25,1\% watched films in Russian; 16,2\% replied that met people who worked or studied in Russia and self-educated.

To the question «how quickly did you adjust» $20,3 \%$ respondents quickly adapted to the climate; $18,7 \%$ agreed that it was easier to adjust to the educational system and socializing; $15,4 \%$ adjusted to campus life faster; $13,8 \%$ adjusted to living away from home; and $13,1 \%$ adapted to studying subjects they never previously studied. The majority of international students $(45,3 \%)$ like living on campus; $33,9 \%$ note that there are problems; $13,2 \%$ don't like it; and 7,6\% gave "another option".

Next question «do you like the major of your choice». The results show that the majority of international students $(92,1 \%)$ like it, and only $1,9 \%$ note that there are problems. $75 \%$ of international students showed an interest in learning, 23,1\% couldn't give a definite answer; and $1,9 \%$ showed no signs of such an interest. $65,4 \%$ of subjects face learning difficulties; $25 \%$ believe they have few or none; and 9,6\% find studying difficult. Answers to «what do you find difficult in the learning process» show main difficulties ASU students face. The most common answer here was «exam preparation» (32,7\%). Then «DIY assignments» $(29,5 \%),(14,9 \%)$ chose not to answer. Also, students note difficult practical assignments $(13,1 \%)$, and $(9,8 \%)$ find listening to lectures difficult.

Replies to «how you assess your knowledge and level of Russian», indicate that the majority of international students know Russian well enough to feel at ease during studies. However, $37,2 \%$ responders would like to supplement their learning process with additional courses of Russian language.

Our next question enabled us to find out what helps international students in their studies. Main assistance $(42,8 \%)$ is provided by entertaining and detailed explanations their instructors give; parental assistance and control (11,9\%); teacher and administrative control $(8,3 \%)$. Thus, we can assert that the support phase of ASU international students is wellorganized. According to our subjects, difficulties in memorizing the material causes most of learning problems $(23,5 \%) ;(13,2 \%)$ of respondents understand the lecture material with difficulty and lack necessary textbooks and manuals in their native language.

When discussing «free time pastimes and hobbies» the students noted: computer activities (16\%), music $(13,2 \%)$; doing nothing, just resting (12\%); sports, tourism, creative hobbies $(10,7 \%)$; part-time work $(5,4 \%)$.

With the help of «Tolerance index» questionnaire we defined general levels and various tolerance aspects in our subjects. The quantitative results analysis shows the predominance of tolerant affirmations in our international students, that average manifestation level corresponds to average selection score, which is 89,3 . Prevalent manifestation levels on all scales under study come off as average $63,4 \%$.

Phinney technique results (for establishing ethnic entity) demonstrated high manifestation levels on a 30 point scale. Only $12,7 \%$ respondents exhibited low levels of ethnic identity, indicative of low affiliation to the subject's ethnic group or even negative attitude towards 
it. Average and high levels of ethnic affinity were demonstrated by $15 \%$ and $44 \%$ of international students which is a positive measure of ethnic correlation, indicating a high mark both within the subjects' own ethnic group and other ethnic groups. It's noteworthy that $30 \%$ of respondents exhibit extreme levels of ethnic identity, indicating extreme importance of the subjects' own ethnic group and the existence standards and ethnic bias towards other ethnic groups as well as lack of interactive tendencies with representatives of such groups.

The Mnatsakanyan technique data analysis (cultural shock level manifestations) revealed the following three subject groups: low manifestations -35 students $-48,30 \%$; medium manifestations -17 students $-22,76 \%$; high manifestations -19 students $-28,94 \%$.

According to the technique, we received the following data: ballpark figure $-3,4 \%$, which correlates to some adjustment difficulties. Most evident emotional manifestations are as follows: medium figure 4,1\% (feeling of loss of loved ones); medium figure 5,2\% (extreme homesickness). Medium culture shock manifestations - fear of communication amounted to $1,2 \%$. Low manifestations of this symptom may relate to the subjects' readiness to communicate with representatives of other cultures and establish amicable contacts in a new cultural environment.

Thusly, our research established that the adjustment process among international students correlates to medium acquisition of ethnic tolerance, marked manifestations of ethnic identity, prevalence of average and high levels of culture shock manifestations, marked social distancing with host culture representatives and evident learning motivation.

Our socio-psychological support program enabled us to achieve positive results, ensuring full educational adaptiveness of our student subjects; speeding and simplifying social and cultural adjustment and presented a complex problem-solving mechanism for our international students. We applied previous experience in tutorial and student adjustment work, recent professional activity stipulations, students' skill and knowledge levels and social and educational development trends.

Our research results were at the core of the program. The aim of the program was to implement a socio-cultural environment conducive to successful learning adjustment among international ASU students.

The first, socio-psychological module, included work patterns of campus tutors, mentors and psychological centers. The core idea was to establish student-tutor trust.

The second, adaptive-educational module, prompted educational immersion, regulation awareness and organizational and paperwork literacy. Student immersion, methodological studies, professional days, student council meetings student monitor training, adjustment sessions, open consultations, extra studies were on the radar of university managers, teaching staff, tutors and dean's office.

The third, adjustment tutorial module focused on speeding the adjustment process. It included:

- university events with international students' participation: «Freshman's Day», «Matriculation», «Student Spring», «Nationhood Day» etc.

- «in the group» events and outings, group meetings and one-on-one tutor sessions.

The last module was health-promoting. It included a variety of health-conducive events, activities and competitions: tennis, volleyball football, running track with both teacher and medical supervision present. Psychological well-being was promoted by group discussions on the topics of drug use, drinking problems, issues of staying fit and medical check-ups of international students' health and well-being.

The implementation of our support program contributed to the beneficial learning environment, comfortable living conditions and personal growth of our subjects. Any student should be able to assess means and tools of activity, as well as recognize the quality and results thereof, alongside with goal setting and self-work algorithm implementation. 


\section{Discussion}

Our empiric research enabled us to prove that student anxiety is a distinctive and social and cultural adjustment-influencing factor among our subjects.

The moment they arrive to our country, international students feel the need for social and cultural adjustment. The success of their adjustment will depend on their problem-solving skills and the ability to cope with culture shock, the degree of their social immersion and their practical knowledge of new social norms and values. A significant part in intercultural adjustment studies belongs to situational anxiety.

After reviewing the results of the main empiric research we qualified it as interim between integration and culture shock. Education of international students in the initial phase is followed by excessive attention from host country representatives and positive emotions and impressions regarding new culture. Further on different social and cultural conditions begin to negatively influence international student's personality. The majority of students start experiencing culture shock, followed by depression and desolation. In this state the majority of students react strongly to miniscule tasks and difficulties, sleep disorder, educational stress and communication anxiety. Since most students do experience culture shock, at this stage it's difficult to distinguish more successful adjustment mechanisms. Closer to the end of their stay students exhibit higher levels of adjustment and well-being due to the imminent return home and their families.

Several years' stay in the host country is considered enough to pass from culture shock to integration. International students strive to cope with their difficulties by achieving a state of well-being in new socio-cultural surroundings.

Communication with the host culture representatives is a primary obstacle as well. Thus we believe it impossible to acquire a high level of socio-cultural competence throughout the period of their stay in new socio-cultural environment without express impact.

International students have specific motives for staying abroad. High levels of learning motivation we revealed in our research relates to the group is focused on receiving higher education, conducive to professional growth and career prospects, enabling them to reach financial prosperity either in their homeland or in any other country.

International students identify themselves with a different student environment; acknowledge its significance when adjusting to new intercultural conditions. However they do not always feel at ease when socializing with representatives of other cultures and note the lack of friendly ties with them. This signals about their aspirations towards intercultural communication and lack of socio-cultural competence.

Personal well-being of an international student presents a key state and is viewed as success / unsuccess criteria of the social and cultural adjustment process. The assessment includes a number of social and psychological features, which are considered universal and are evident in international students' social behavior while reflecting primary cooperation spheres (communication, studying household problems). On some technique scales our study results differ in their manifestation, which enables us to analyze adjustment specifications of students from Turkmenistan, Syria, Palestine, Mongolia, Africa.

Research data acquired during the summative and formative stages enable us to distinguish successful socio-cultural adjustment criteria of international students.

It includes: high ethnic tolerance level; low level of marked culture shock; detachment and social distancing from host culture representatives; use of interactive adjustment types.

Summarizing the implementation of our socio-cultural support program we determined that the adjustment levels within our experimental group definitely increased. Furthermore, we distinguished «tension and sensitivity» scale and «features of psycho-emotional symptomatology», both with significant variables. 
The success of the whole adjustment process depends on primary socio-psychological features of international students within new social and cultural environment implemented by their educational establishment.

\section{Conclusions}

Adjustment process developments among international students become possible only in correlation between them and the new intercultural environment. International students with high levels of tolerance, interactivity, subjective well-being and low levels of marked culture shock, depression and anxiety are more adaptable to unfamiliar multicultural environment.

Highly adaptive international students belong to the interactive type. They exhibit immersion readiness for unfamiliar intercultural conditions, striving to broaden their social circle with the representatives of other cultures, aim at joint problem-solving, as well as exhibiting fewer signs of loneliness. By reference to the students with lower adjustment levels, they exhibit medium manifestation of psycho-emotional symptomatology signs together with affective and cognitive components of ethnic identity. They exhibit a medium level of cultural shock and tolerance, social distancing and average subjective well-being as well. These features are common for the unfinished adjustment process among international students.

Thusly, we distinguish external and intrinsic factors which influence smooth adjustment process: from every student's individual efforts and personal features to the living adjustment system implemented in the chosen educational establishment. The results of the study point out that intercultural adjustment of international students is more successful in compliance with the support program implemented according to socio-psychological traits of international students and newly existing conditions of socio-cultural environment.

An intrinsic condition of successful socio-cultural adjustment among international students is the implementation of social and psychological support program by the staff of educational and cultural establishments. The system is a wholesome activity course highly dependable on the immersion of international students in new multicultural conditions. The support program encompasses main areas of student life, which is a distinct advantage. Its adaptable structure adjusts to all possible alterations to be implemented in various groups and different conditions.

Feasibility and validity of our reasoning is concurred by the depth and balance of international students' adjustment problem review. Our empiric multiphase study concludes with achieving positive results as well as proposed tasks and purposes. Thus, our hypothesis is proven valid.

Note that the obtained data could prompt further research on the subject. We believe that studying perceptions of international students in all areas of their life could be a promising area of research because they largely control their attitude. Equally promising is the research of impact peculiarities on the successful adjustment process within the students' social circle. Such research will prove highly conducive to the extension and classification of scientific views on social and cultural adaptation of international students.

\section{References}

1. E.N. Reznikkov, Vestnik PFUR, "Psychology and pedagogics" series 1 (2010)

2. I.V. Tyuryapina, The world of science, culture, education 1(56) (2016)

3. E.D. Maksimchuk, TSPU Bulletin 11(164) (2015)

4. E.D. Koval, Scientific notes of Lesgaft Institute 10(152) (2017) 
5. C.V. Shtak, Pecularities of socio-psychological adjustment of representatives of various social outsider groups. dis... Candidate for Psychological Sciences (Kemerovo, 2016)

6. I.A. Miloslavova, Definition and structure of social adaptation: dis...Candidate for Philosophical Sciences (2015)

7. A.A. Rean, A.R. Kudashev, A.A. Baranov, Psychology of personality adjustment (Praim-EVROZNAK, SPb, 2018)

8. A.A. Sukhanov, Humane vector 2(26) (2011)

9. A.V. Tairova, Materiály XI mezinárodnívědecko - praktickákonference «Efektivnínástrojemoderníchvěd - 2015» (Publishing House «Education and Science», Praha, 2015)

10. A.G. Maklakov, Psychological Journal 22(1), 16-24 (2016)

11. E.V. Kaluyshnikova, Vestnik TvSU. "Psychology and pedagogics" series 1 (2018)

12. T.G. Stefanenko, Ethnic psychology: university students' manual (Moscow: Aspect Press, 2013)

13. G.U. Soldatova, O.A. Kravtsova, O.E. Khulaev et al, Psychologists on migrants and migrations in Russia: inf. - analit. Bulletin 4, 59-65 (2002)

14. I.A. Mnatsakanyan, Student adjustment to new socio-cultural conditions: diss. Candidate for Psychological Sciences (Yaroslavl, 2004)

15. A.N. Tatarko, Ethnic and cross-cultural psychology methods: student manual (HSE HSE Publishing house, Moscow, 2011)

16. I.A. Sholokhov, Psychological adjustment peculiarities of young people studying abroad: dis...Candidate for Psychological Sciences (M., 2002)

17. V.V. Konstantinov, Personality adaptation: theory and diagnostics: student manual (Belinsky State University, Penza, 2005) 